REVIEW PAPER

\title{
RHEOLOGICAL METHOD FOR DETERMINATION OF CRITICAL CONCENTRATION OF PECTIN DISPERSION - A REVIEW
}

\author{
URAY ULFAH NABILAH ${ }^{1}$, AZIS BOING SITANGGANG ${ }^{1}$, EKO HARI PURNOMO$^{1}$ \\ ${ }^{1}$ Department of Food Science and Technology, Faculty of Agricultural Engineering and \\ Technology, IPB University, Bogor 16680, Indonesia \\ *corresponding author: h.purnomo@apps.ipb.ac.id
}

Received on 23 August 2021

Revised on 11 October 2021

\begin{abstract}
Pectin critical concentration is a parameter that determines the effectiveness of pectin as a thickening and gelling agent. A lower critical concentration indicates the ease of a particular hydrocolloid to thicken the solution or form gel. From the industrial point of view, this is of interest as it entails a lower production cost. This review examines the critical advantages and limitations of various methods in determining the rheological-based critical concentration of pectin. The methods discussed in this work were based on dynamic viscosity flow pattern $(\eta)$ plotted against shear rate $(\gamma)$, apparent viscosity $\left(\eta_{a p p}\right)$, zero shear viscosity $\left(\eta_{0}\right)$, and consistency index $(K)$ plotted against concentration $(c)$, and specific viscosity $\left(\eta_{s p}\right)$ plotted against the dimensionless number $(c[\eta])$. Empirically, these methods have been shown to successfully predict critical concentrations of pectin. However, models that can be used generally for each type of pectin flow are (1) $\eta_{0}$ plotted against $c$ and (2) $\eta_{s p}$ plotted against $c[\eta]$. Conclusively, this review provides information for industries and researchers to select a suitable method for analyzing the critical concentration of pectin where variations might be present due to different sources and methods for extraction.
\end{abstract}

Keywords: critical concentration, pectin, rheology, viscosity

\section{Introduction}

Pectin is a hydrocolloid often used by the food and pharmaceutical industries as a gelling agent (Pan et al., 2021), emulsifier (Zhang et al., 2020), stabilizer, and thickener (Agudelo et al., 2014; Yapo, 2011; Erçelebi and Ibanoğlu, 2009; Codex, 2018). The demand for pectin production shows an increasing number. This could be seen from the global pectin production in 2009 of 30000 tonnes/year then

https://doi.org/10.35219/foodtechnology.2021.2.12 
increased to 60000 tons/year in 2015 (Ciriminna et al., 2016). Pectin is one of the most widely used hydrocolloids because pectin provides not only functional (Sitanggang et al., 2010; Sakooei-Vayghan et al., 2020) but also health benefits (Figueroa and Genovese, 2018; Tan and Nie, 2020; Muñoz-Almagro et al., 2020; Liu et al., 2020).

The use of hydrocolloids in the food industry is closely related to the rheological properties and appearance of the product (Laguna et al., 2020; Funami et al., 2012). The long-chain polymer structure in hydrocolloids is water-soluble and can swell in it, thus could potentially change the rheological properties of the solution ( $\mathrm{Li}$ and Nie, 2016). One of the essential parameters that determine the functional quality of pectin is the critical concentration ( $\left.c^{*}\right)$ (Rodrigues et al., 2020). If the viscosity can only represent coil interaction or coils-solvent interaction when it is deformed, the critical concentration not only defines the conditions of the interaction but also the concentration at which the interaction between the coils begins. The interaction between the coils occurs due to the total volume occupied by the polymer, which almost fills the total volume of the solution (Sayah et al., 2016). The easier the coils interact, the lower the critical concentration produced. The critical concentration may reflect characteristics that are not visible in pectin. Indirectly, the critical concentration is the appearance of the molecular particles and the appearance of the interaction between internal and external factors present in the solution. Knowledge of critical concentration is important in analyzing flow dynamics (Rodrigues et al., 2020), transportation of pipeline systems in the industry, and as a reference for using the amount of pectin concentration to achieve a certain degree of viscosity.

In general, polymers are in the form of long coils that can interact with solvents and interact with each other at certain concentrations, so the determination of the critical concentration of pectin can also be applied to other polymers, even though they have different rheological properties. Determination of critical concentration has variations in methods, due to differences in sample sources and preparation methods, types, and specifications of instrument used. One of the fatal problems in predicting critical concentration is the assumption that all predictive methods can be used for every type of pectin. Not all methods can be used for all types of pectin because each material has specific flow behavior that is influenced by intrinsic and extrinsic factors. This is based on Newton's viscosity law which states that there are two kinds of flow, Newtonian and non-Newtonian (George and Qureshi, 2013). Flow behavior has an enormous effect on viscosity which has an impact on critical concentrations. When the prediction model used does not match the flow behavior, it will be difficult to produce accurate information. Each existing method will have advantages and disadvantages. There are many studies related to critical concentrations, particularly on pectin, but the information related to existing methods is still scattered and has not been compared with one another. In addition, existing studies do not clearly explain the reasons for using the chosen method, even though the precision of the method is important to generate predictions that are close to the true value. To date, there is no review article that discusses the 
various methods of determining critical concentration specifically for pectin. Based on the background described, the purpose of this review is to explain various methods of determining critical concentration. The content of this review includes the description of critical concentration, analytical methods for determining the critical concentration, and the critical issue in each method. This review can be used as a piece of information for researchers and industrial practitioners to choose a suitable critical concentration prediction method, especially for pectin.

\section{The critical concentration of pectin}

Pectin has many hydroxyl groups $(-\mathrm{OH})$, which can increase the affinity to bind water molecules. It can produce colloid dispersion which affects the rheological properties of the food system, both flow behavior and solid behavior. One of the most important parameters in the study of dispersion rheology of pectin is viscosity (Einhorn-stoll, 2018; Saha and Bhattacharya, 2010). Viscosity is a physical property of the fluid which describes the resistance to flow and is calculated as a ratio of shear stress and shear rate $(\eta=\tau / \gamma)$ (Kasapis and Bannikova, 2016). Generally, an increase in concentration will be accompanied by an increase in viscosity (Zhang et al., 2016).

The basic critical concentration concept of polymer is a transition point from dilute $\left(c<c^{*}\right)$, semi-dilute $\left(c^{*}<c<c^{* *}\right)$, and concentrated dispersion $\left(c^{* *}<c\right)$, which can be known from the slope change of rheological parameter value (i.e. viscosity, see Figure 1) (Benchabane and Bekkour, 2008; Rao, 2007).

There are two critical concentration terms in polymer, overlapping critical concentration $\left(c^{*}\right)$ and entanglement critical concentration $\left(c^{* *}\right)$ (John et al., 2019). Kale et al. (2015) showed that there is a negative correlation between viscosity and critical concentration. At low concentrations, polymer coils have a tenuous radius, are independent, and do not interact with each other so that the coils can move freely which makes the viscosity relatively low (Kale et al., 2015). In this condition, it can be said that the solution is dilute $\left(c<c^{*}\right)$. Dilute solution study is used to understand the basic properties of the polymers like polysaccharides (i.e. conformation, molecular weight, molecular weight distribution, and interaction properties) (Rao, 2007). The overlapping critical concentration is a narrow concentration range of solution $\left(c=c^{*}\right)$, in which polymer coils start to interact and form overlapping coils. When the concentration of polymer in a solution is above $c^{*}$, the viscosity can increase sharply if there is an addition of polymer (Vinogradov and Titkova, 1968; Saha and Bhattacharya, 2010; Cui, 2005). The increase of concentration above the $c^{*}$ point causes the polymer to enter the semi-dilute regime $(c>c *)$. In the semi-dilute regime, there are physical interactions (mutual penetration and entanglement) between coils that are near to each other (Kale et al., 2015; Rao, 2007; Rodrigues et al., 2020). Dispersion will enter a transition state from dilute to concentrated $\left(c=c^{* *}\right)$, in which the polymer chains formed a network or entanglement, as concentration increases. Indirectly, the information on the range of dilute to semi-dilute regions can describe 
conditions of the product at a higher concentration level. In optimizing product production, lower concentration conditions will be preferred because they can reduce the cost burden. Based on this, there is a strong reason why the studies of polysaccharide dispersions reported, especially for food applications, are mostly reported dilute and semi-dilute regimes $\left(c<c^{*}<c\right.$ ) (Cui, 2005; Benchabane and Bekkour, 2008).

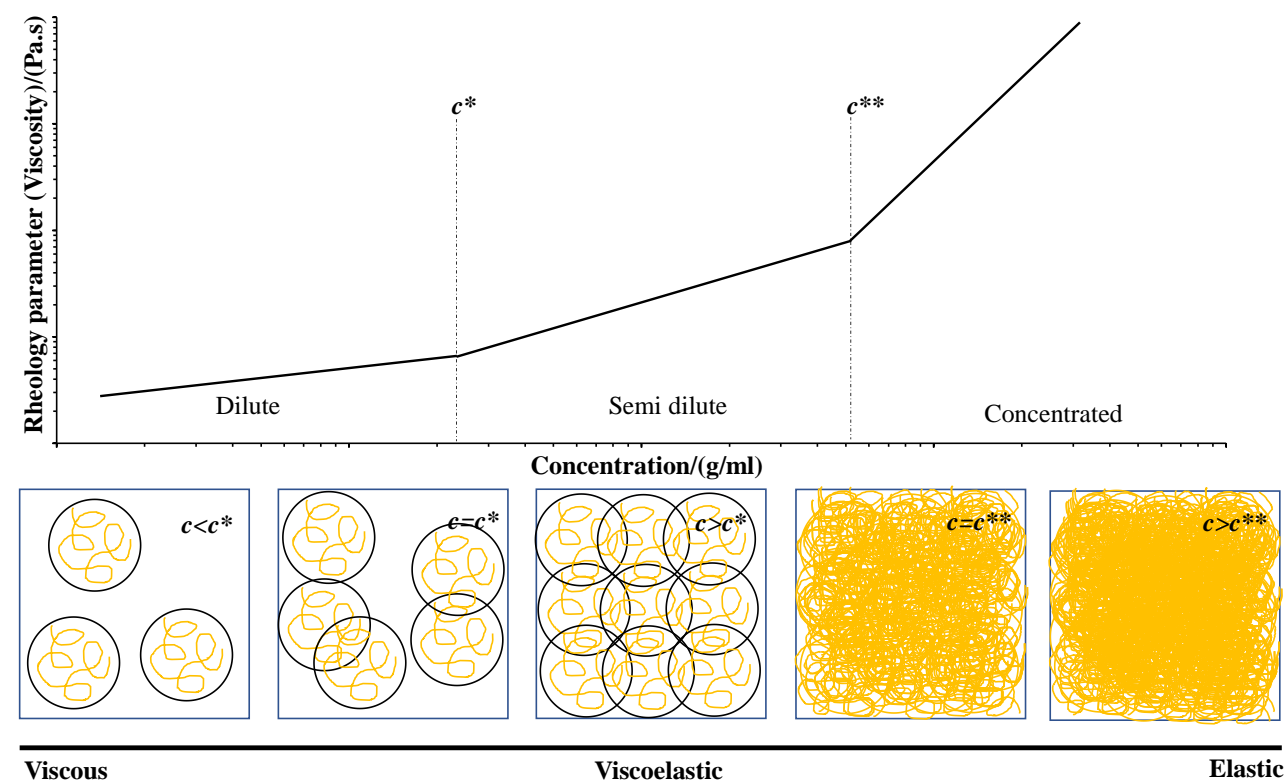

Figure 1. The viscosity of polymer dispersion as a function of concentration in the dilute, semi dilute, and concentrated regime as well as a schematic overview of its constituent polymer interactions (modified from Rayner et al (2016)).

Especially for pectin dispersion, it behaves as a Newtonian fluid when the concentration is below $c^{*}$, and as the concentration rises above $c^{*}$ such nonNewtonian (shear-thinning) flow behavior is observed (Methacanon et al., 2014; Endress et al., 1996; Lopes et al., 2014). This condition also applies generally to the other hydrocolloids (Li and Nie, 2016). A study by Kontogiorgos et al. (2012) showed the property of okra pectin is Newtonian in low concentration $(c<\sim 1 \%$ $(m / V)$ or $c<c *)$ and it has shear-thinning behavior in the high concentration $(c>\sim 1$ $\%(m / V)$ or $\left.c>c^{*}\right)$. The knowledge of the flow behavior of pectin is very important to obtain the desired product viscosity without changing other product attributes (Morales-Contreras et al., 2020). The information on the critical concentration of pectin is indirectly linked to the ability of pectin to form a gel. When the concentration is higher than $c^{*}$, a number of chains are sufficient to form a junction zone and three-dimensional networks to form a gel with a stronger consistency (Colodel et al., 2019). The lower value for $c^{*}$ of pectin shows a lower concentration needed to form a gel. 


\section{Factors affecting critical concentration}

In the literature (Table 1), it has been shown that different sources and methods of pectin extraction can result in different $c^{*}$ values.

Table 1. Critical concentration of pectin in several studies.

\begin{tabular}{|c|c|c|c|c|}
\hline Source & Solvent & $\begin{array}{l}\text { Extraction process } \\
\text { DM/DE }\end{array}$ & $\begin{array}{l}c^{*} \% \\
(m / V)\end{array}$ & References \\
\hline \multirow{5}{*}{ Citrus } & \multirow{5}{*}{$\begin{array}{l}0.1 \mathrm{M} \mathrm{NaCl} \text { at } \\
\mathrm{pH} 7.0\end{array}$} & DM $72 \%$ & $0.13^{\mathrm{a}^{*}}$ & Axelos et al. (1989) \\
\hline & & DM $53 \%$ & $0.15^{\mathrm{a}^{*}}$ & Axelos et al. (1989) \\
\hline & & DM $45 \%$ & $0.19^{\mathrm{a}^{*}}$ & Axelos et al. (1989) \\
\hline & & DM $38 \%$ & $0.17^{\mathrm{a}^{*}}$ & Axelos et al. (1989) \\
\hline & & DM $30 \%$ & $0.17^{\mathrm{a}^{*}}$ & Axelos et al. (1989) \\
\hline \multirow{2}{*}{$\begin{array}{l}\text { Okra } \\
\text { (Abelmoschu } \\
\text { s esculentus) }\end{array}$} & \multirow{2}{*}{$\begin{array}{l}0.1 \mathrm{M} \mathrm{NaCl} \text { at } \\
\mathrm{pH} 7.0\end{array}$} & $\begin{array}{l}\text { Hot buffer soluble } \\
\text { solids (HBSS) }\end{array}$ & $0.83^{b^{*}}$ & $\begin{array}{l}\text { Kontogiorgos et al. } \\
\text { (2012) }\end{array}$ \\
\hline & & 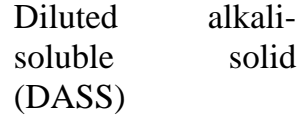 & $1.23^{\mathrm{b}^{*}}$ & $\begin{array}{l}\text { Kontogiorgos et al. } \\
\text { (2012) }\end{array}$ \\
\hline $\begin{array}{l}\text { Pomelo } \\
\text { (Citrus } \\
\text { maxima) }\end{array}$ & $\begin{array}{l}\text { Deionized } \\
\text { water }\end{array}$ & DE $58 \%$ & 0.55 & $\begin{array}{l}\text { Methacanon et al. } \\
\text { (2014) }\end{array}$ \\
\hline \multirow{4}{*}{$\begin{array}{l}\text { Okra } \\
\text { (Abelmoschus } \\
\text { esculentus L.) }\end{array}$} & \multirow{4}{*}{$\begin{array}{l}\text { pH } 7.0 \text { in } \\
\text { Sorensen's } \\
\text { phosphate } \\
\text { buffer } \\
\text { pH } 3.0 \text { citric } \\
\text { buffers in } 0.1 \\
\mathrm{M} \mathrm{NaCl}\end{array}$} & pH 2 DM $40 \%$ & $0.37^{b^{*}}$ & Alba et al. (2015) \\
\hline & & pH 3 DM $40 \%$ & $0.45^{b^{*}}$ & Alba et al. (2015) \\
\hline & & pH 7 DM $24.4 \%$ & $0.15^{b^{*}}$ & Alba et al. (2015) \\
\hline & & pH 3 DM $24.4 \%$ & $0.44^{\mathrm{b}^{*}}$ & Alba et al. (2015) \\
\hline \multirow{3}{*}{$\begin{array}{l}\text { Lemon juice } \\
\text { waste (Citrus } \\
\text { limon L.) }\end{array}$} & \multirow{3}{*}{$\begin{array}{l}0.1-20 \mathrm{~g} \cdot \mathrm{L}^{-1} \\
\text { citric buffer } \mathrm{pH} \\
3.5\end{array}$} & $\begin{array}{l}\text { Lemon albedo DM } \\
59.3 \%\end{array}$ & $0.30^{\mathrm{b}^{*}}$ & $\begin{array}{l}\text { Dimopoulou et al. } \\
\text { (2019) }\end{array}$ \\
\hline & & $\begin{array}{l}\text { Lemon core parts } \\
\text { and membranes } \\
\text { DM } 51.4 \%\end{array}$ & $0.06^{b^{*}}$ & $\begin{array}{l}\text { Dimopoulou et al. } \\
\text { (2019) }\end{array}$ \\
\hline & & $\begin{array}{l}\text { Lemon extract DM } \\
46.9 \%\end{array}$ & $0.05^{b^{*}}$ & $\begin{array}{l}\text { Dimopoulou et al. } \\
\text { (2019) }\end{array}$ \\
\hline $\begin{array}{l}\text { Apple } \\
\text { (Blanca de } \\
\text { Asturias) }\end{array}$ & $\begin{array}{l}\text { Deionized } \\
\text { water }\end{array}$ & DM $63 \%$ & 1.50 & $\begin{array}{l}\text { Morales-Contreras } \\
\text { et al. }(2020)\end{array}$ \\
\hline $\begin{array}{l}\text { Riang (Parkia } \\
\text { timoriana } \\
\text { (DC.) Merr.) } \\
\text { pod }\end{array}$ & $\begin{array}{l}\text { Deionized } \\
\text { water }\end{array}$ & $\begin{array}{l}\text { Riang pod husk DE } \\
66.2 \% \\
\text { Riang pod powder } \\
\text { DE } 66.3 \%\end{array}$ & $\begin{array}{l}1.2 \\
1.5\end{array}$ & $\begin{array}{l}\text { Buathongjan et al. } \\
\text { (2020) }\end{array}$ \\
\hline
\end{tabular}

Generally, the intrinsic factors which affect the critical concentration of pectin are the degree of esterification (DE) (Schmidt et al., 2015; Monsoor et al., 2001; Sundar Raj et al., 2012; Narasimman and Sethuraman, 2016; Morris and 
Binhamad, 2020), acetyl groups (Kpodo et al., 2018), degree of polymerization (DP), protein groups (Pacheco et al., 2019), distribution of carboxyl groups (Sundar Raj et al., 2012), the charge of pectin molecule (Kale et al., 2015; Lewicki, 2004), chemical conformation, and particle morphology (Morris and Ralet, 2012; Einhorn-stoll, 2018; Einhorn-Stoll et al., 2012). Some studies showed that an increase in molecular weight (Jin-hua et al., 2008; Schmidt et al., 2015; Kale et al., 2015; Fu et al., 2010), branch chains (Ngouémazong et al., 2012; Wang et al., 2021), and neutral sugar groups (Constenla and Lozano, 2003; Morris and Ralet, 2012) has a direct effect on the decreasing of critical concentration.

Dispersant, which is an external factor, affects the critical concentration obtained. Generally, the solvent used as a dispersing medium is deionized water (MoralesContreras et al., 2020; Methacanon et al., 2014) and sodium chloride solution (e.g., $0.1 \mathrm{M} \mathrm{NaCl}$ ) (Alba et al., 2015; Axelos et al., 1989; Kontogiorgos et al., 2012). The purpose of using deionized water is to minimize the effect of ions, which can increase viscosity, especially for Low Methoxyl Pectin (LMP) (Yang et al., 2018). Whereas the use of $\mathrm{NaCl}$ is to maintain constant ion strength (Sayah et al., 2016). Another critical factor is the preparation of pectin dispersion. Pectin is a polymer with less hydrophilic characteristics compared to other carbohydrate-based hydrocolloids due to the presence of hydrophobic groups (Einhorn-stoll, 2018), such as the methyl ester group (Monsoor et al., 2001; Sundar Raj et al., 2012; Narasimman and Sethuraman, 2016; Schmidt et al., 2015) and the acetyl group (Kpodo et al., 2018). Therefore, previously reported studies on critical concentration measurements were carried out by overnight stirring to obtain homogenous pectin dispersion (Axelos et al., 1989; Kontogiorgos et al., 2012; Alba et al., 2015; Dimopoulou et al., 2019; Morales-Contreras et al., 2020; Methacanon et al., 2014). Generally, the extrinsic factor that affects critical concentration associated with the condition of the environment such as ionic strength (Colodel et al., 2019), pH (Alba et al., 2015), temperature (Cui, 2005), the presence of other dissolved substances (Constenla and Lozano, 2003; Singh and Heldman, 2009; Zhong and Daubert, 2013; Cullen, 2012; Morris and Binhamad, 2020), and mechanical energy (e.g. stirring intensity) (Einhorn-stoll, 2018). However, these factors affect not only critical concentration but also the kinetics of polymer dissolution (Miller-Chou and Koenig, 2003).

\section{Critical analysis of critical concentration models}

The concept of critical concentration determination based on rheological properties assumes that there is no steric interaction and friction in the coils (Clasen et al., 2006). Hereby, the critical concentration is based on the correlation between viscosity and polymer concentration (Figure 1 and Figure 2). 


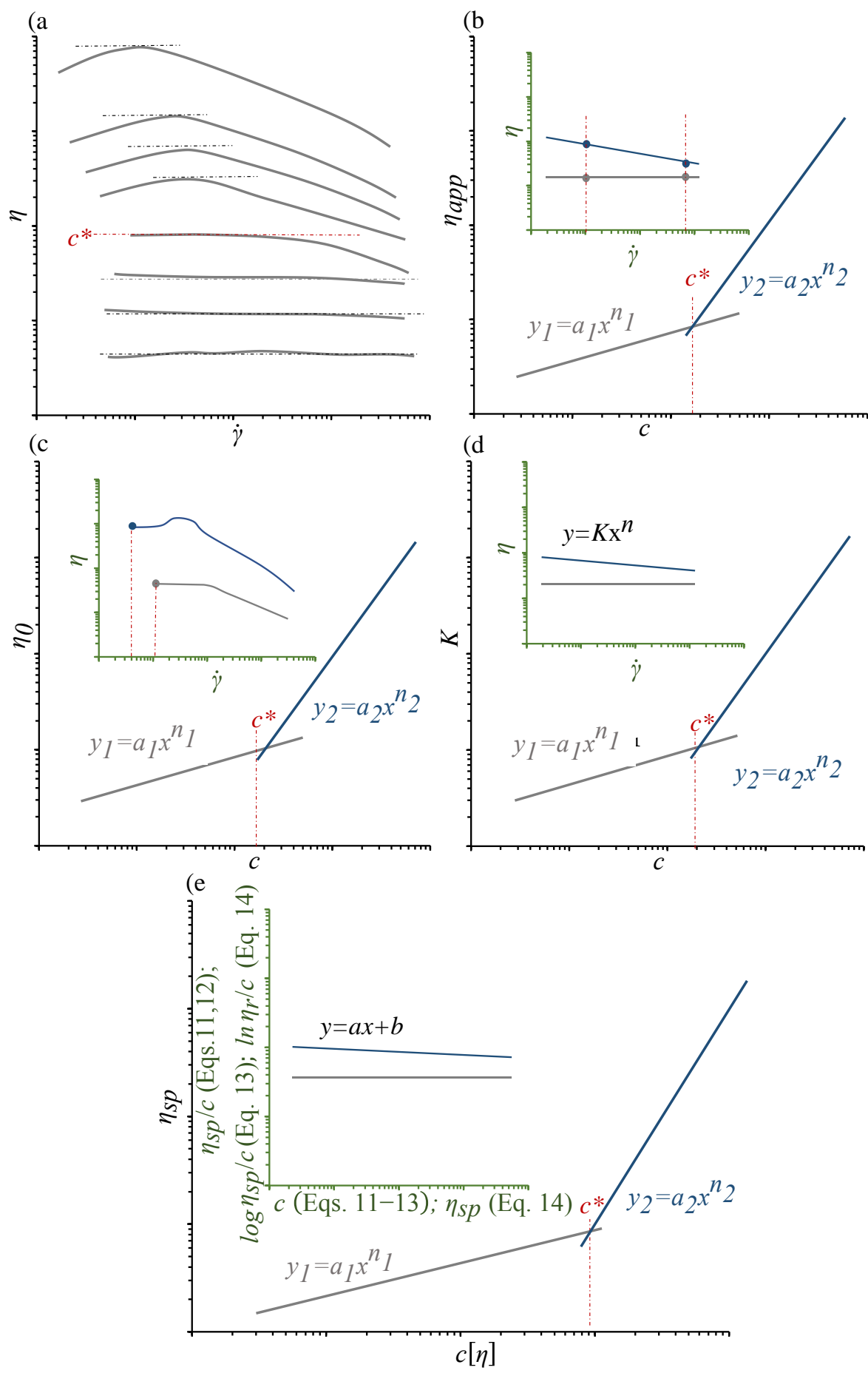

Figure 1. Various models to predict critical concentration (a) $\eta v s . \dot{\gamma}$, (b) $\eta_{\text {app }} v s . c$, (c) $\eta_{0}$ vs. $c$, (d) $K$ vs. $c$, and (e) $\eta_{s p} v s . c[\eta]$. 
The viscosity can be represented by different embodiments, such as dynamic viscosity $(\eta)$, apparent viscosity $\left(\eta_{a p p}\right)$, zero shear viscosity $\left(\eta_{0}\right)$, consistency index $(K)$, and specific viscosity $\left(\eta_{s p}\right)$ (Figure 2 ).

Generally, the range of pectin concentration to determine $c^{*}$ is $0.1-3 \%(\mathrm{~m} / \mathrm{V})$ (Morales-Contreras et al., 2020; Methacanon et al., 2014). One must be aware that the more dilute the solution, the more the sensitivity of the instrument is needed to measure the viscosity (Rodrigues et al., 2020). The concentrations of pectin dispersion must represent dilute and semi-dilute regimes. There should be at least three concentration points for each region. In general, the viscosity increases along with the increase in concentration. The higher the concentration, the viscosity will increase differently depending on the internal properties of the polymer. By this, two different regimes separated by different slope values can be observed (Morris et al., 1981; Yang and Yuan, 2018). The critical concentration can be thus, determined based on the transition point when the viscosity change drastically or at the intersection point between two lines that represent dilute regime and semidilute regime (Kale et al., 2015).

\section{Dynamic viscosity pattern}

Dynamic viscosity pattern is a collection of viscosity values from the ratio of shear stress and shear rate in Newton's viscosity law as defined in Equation 1.

$$
\eta_{\text {app }}=\frac{\tau}{\gamma_{i}}
$$

The prediction of critical concentration using dynamic viscosity flow pattern is by having a viscosity as a function of shear rate (Figure 2a). As mentioned above, the increase in pectin concentration can shift the flow behavior of pectin suspension. At low concentration $\left(c<c^{*}\right)$, the flow behavior is Newtonian, in which the shear rate effect is very small or negligible because the viscosity does not show a significant change. However, when the concentration has entered critical concentration or more $\left(c>c^{*}\right)$, the flow behavior changes to a little shear thinning and becomes very strong in shear-thinning properties. In this condition, it will appear that the viscosity will depend on the shear rate. The shear-thinning condition is due to the re-entanglement rate being slower than the entanglement rate (Arora et al., 2016). Flow pattern that shows a transition pattern can be used to predict the critical concentration (Benchabane and Bekkour, 2008). This method can be used as a preliminary method because this seems to be a simple one, but it can be tough since one must precisely obtain the critical concentration through the pattern obtained. In this method, the transition line cannot be extrapolated to obtain a more detailed critical concentration point. Hereby, this method is rarely used to predict critical concentration. Benchabane and Bekkour (2008) reported successful prediction of a critical concentration of carboxymethyl cellulose (CMC) using this method. The results were validated by zero shear viscosity and specific viscosity. Although Methacanon et al. (2014) and Pancerz et al. (2020) could obtain the dynamic viscosity pattern for pectin dispersion, especially at the Newtonian plateau regime, they still predicted $c^{*}$ using a zero shear rate. The accuracy of dynamic 
viscosity flow pattern-based critical concentration determination is highly dependent on the concentration interval employed.

\section{Apparent viscosity}

Apparent viscosity $\left(\eta_{a p p}\right)$ is viscosity measured at a certain shear rate $\left(\gamma_{i}\right)$ following Equation 1 (Rodríguez de Castro and Agnaou, 2019). If the flow behavior is Newtonian, the number of apparent viscosity obtained will be the same in different shear rate values (Morris et al., 1981). Meanwhile, when the flow behavior is nonNewtonian, the apparent viscosity deviates following shear rate values. Based on this, the changes in viscosity can be observed for shear-thinning (pseudoplastic fluid) and shear-thickening (dilatant fluid) (Funk and Dinger, 1994). It must be noted that extrapolation must not be performed to calculate apparent viscosity whenever the measurement settings are beyond the instrument quantification capacity. This was also reported by Funk and Dinger (1994) in which the number obtained from mathematical extrapolation is not mechanically reliable in the fluid. Rodríguez de Castro and Agnaou (2019), there is a tendency for different flow patterns along with different shear rate values for certain polymers.

The determination of $c^{*}$ using apparent viscosity can be carried out by plotting apparent viscosity as a function of concentration, this method shows in Figure $2 \mathrm{~b}$. The measurement of apparent viscosity is based on the interaction within polymer chains, which depended on the molecular weight (Yang and Yuan, 2018). This condition makes apparent viscosity an indirect representation of material molecular weight. The apparent viscosity-based critical concentration determination can be adjusted with specific shear rate values (inset of Figure $2 b$ ) and makes this method more feasible. The measurement of apparent viscosity is relatively fast due to onepoint measurement. The apparent viscosity-based critical concentration determination is considered a simple method as it needs only a rotary viscometer to measure viscosity value at one specific shear rate. Cited as an example, a shear rate of $50 \mathrm{~s}^{-1}$ is used as a representative condition in describing the mastication and swallowing process based on NDD (National Dysphagia Diet) standard (Popa Nita et al., 2013). The value of apparent viscosity in Newtonian or slightly shearthinning flow will give a more representative critical concentration value because the viscosity values are relatively the same at different shear rates. Similar or relatively close viscosity values at different shear rates will give critical concentration values with minimal deviation.

Several factors are considered when determining the $c^{*}$ value using apparent viscosity that is the instrument used and the flow of behavior information. During the measurement, the instrument must achieve the targeted shear rate to omit any extrapolation taking place. When a rotary viscometer is used, one must have the estimated viscosity value of the fluid beforehand. Cardoso de Castro et al. (2016) showed that measuring viscosities above $5000 \mathrm{mPa} \cdot \mathrm{s}$ using Brookfield rotary viscometer resulted in less accurate values compared to rheometer because rotary viscometer has a limited range of shear rate and less accurate value of actual angular velocity. In addition to the instrument capacity, the flow behavior index (n) is also the highlighted factor for determining the $c^{*}$ value, especially for shear 
thickening or shear-thinning fluid. Pectin dispersion shows shear thinning behavior at elevated concentrations. With this, the flow behavior index of the suspension must be measured instead of apparent viscosity because of the limitation that cannot represent all of the flow regimes. Therefore, apparent viscosity-based critical concentration study of pectin dispersion is still limited. Pectin dispersion usually exhibits Newtonian behavior at low shear rates but can drastically change as the shear rate increases (Chan et al., 2017). One of the studies on pectin that used apparent viscosity as a parameter to determine critical concentration is a study by Ström, Schuster, and Meng (2014). In this study, the shear rate used was $10 \mathrm{~s}^{-1}$, but the flow properties of the pectin tested were unknown. Besides that, several studies reported successful critical concentration determinations using apparent viscosity. Liu et al. (2014) investigated the critical concentration of several polyacrylamide types (PAM) at a shear rate of $7.34 \mathrm{~s}^{-1}$, where it was known that the flow properties possessed by PAM were slightly shear thinning in the concentration range used to measure critical concentrations. Another study is in an article written by (Yang and Yuan, 2018) on polyimide precursor-polyamic acid (PAA), but it did not show the shear rate and material flow properties.

\section{Zero shear viscosity}

Polymer dispersion shows shear-thinning flow behavior in general (Morris et al., 1981). Pectin shows Newtonian behavior at low concentration $(\sim c<c *)$ and shear thinning behavior at high concentration $\left(\sim c>c^{*}\right)$ (Methacanon et al., 2014; Endress et al., 1996). The decrease of viscosity at dilute solution along with the increase of shear is negligible since the polymer coils have structural elongation and the flow has the same direction. The shear-thinning characteristic will be more visible in the concentrated solution $\left(\sim c=c^{*}\right.$ or $\left.\sim c>c^{*}\right)$ because of the increased interpenetration of polymer coils in the solution due to dynamic entanglement, this depends on the conditions of the pectin used. Such Newtonian flow behavior occurs at a low shear rate (close to zero) because the entanglements in the concentrated solution are disrupted and replaced by the formation of new entanglements in the same or different coils without changing the number of entanglements. That is why the decrease of viscosity will not occur (Lam et al., 2015). The inset of Figure 2c shows that an increase in shear rate will decrease viscosity. The regime with the highest (apparent) viscosity, the asymptotic point at the lowest shear rate produces the plateau area or Newtonian region labeled as zero shear viscosity $\left(\eta_{0}\right)$ (Chhabra and Uhlherr, 1979; Morris et al., 1981; Pancerz et al., 2020).

As a unique molecular representation, zero shear viscosity can be used as a reference to determine the critical concentration (Figure 2c) (Rayner et al., 2016). Zero shear viscosity depends on the chemical type, temperature, molecular weight, number of branch chains, solution concentration, solvent, and instrument sensitivity (Morris et al., 1981; Lam et al., 2015). In general, zero shear viscosity is dependent on molecular weight. The greater the molecular weight, the higher the zero shear viscosity. Likewise, the higher the concentration, the higher the zero shear viscosity value (Larson and Desai, 2015). Pectin has a wide range of zero 
shear viscosity in dilute solution and becomes narrower with the increase of concentration (Sousa et al., 2015; Methacanon et al., 2014). Hereby, the Newtonian regime might be taken to determine zero shear viscosity, and thus for the prediction of critical concentration. The challenge for determining zero shear viscosity is to have a highly sensitive instrument that can operate at shear rates as low as possible (Clasen et al., 2006). This is because polymers with high molecular weight are susceptible to shear forces so that the flow properties of zero shear viscosity are challenging to detect by the tool (Wolf, 2020). Meanwhile, pectin is a polymer that has a big molecular weight (Sayah et al., 2016; Chen et al., 2015). The commercial pectin molecular weight range is approximately $1.9 \cdot 10^{5} \pm 3 \cdot 10^{4}$ $\mathrm{g} / \mathrm{mol}-1.95 \cdot 10^{5} \pm 5 \cdot 10^{3} \mathrm{~g} / \mathrm{mol}$ (Sayah et al., 2016), so it is possible that the instrument cannot detect the zero shear viscosity. Therefore, there is a prediction model for zero shear viscosity, which has been validated for several polymers at Equation 2. Equation 2 is the most used equation for all polymer conditions. In Equation 2, it was assumed that the solvent in pectin is not directly involved in the test process, where the solution viscosity $(\eta)$ is divided by the solvent viscosity $\left(\eta_{\infty}\right)$ (Equation 3), labeled as relative viscosity $\left(\eta_{r}\right)$. The values of $\beta, \alpha$, and $\gamma$ are system's specific hydrodynamic parameters of polymer. The value of $\alpha$ can be assumed to be zero, but this will depend on the type of polymer used. Concentration $(c)$ is the relationship between mass $(m)$ divided by volume $(v)$ $(c=m / V)$. The value of $\tilde{c}$ is assumed to have the same value as the coil overlap parameter (Equation 4) (Wolf, 2020), even though the value of $\tilde{c}$ does not represent the change in the dimension of the polymer coil molecularly (Wolf, 2015). Wolf (2020) reported that Equation 2 produced an error of 5\% in all toluene/polystyrene concentrations, while at low concentrations $(c<0.01 \mathrm{~g} / \mathrm{ml})$ the resulting error value is $15 \%$. However, Equation 2 has not been used in determining the prediction of zero shear viscosity pectin.

$$
\begin{aligned}
& \ln \eta_{r}^{o}=\frac{\tilde{c}+\alpha \tilde{c}^{2}}{1+\beta \tilde{c}+\gamma \tilde{c}^{2}} \\
& \ln \eta=\frac{\ln \eta}{\eta_{\infty}}=\ln \eta_{r} \\
& \tilde{c}=c[\eta]
\end{aligned}
$$

In pectin, zero shear viscosity is affected by its branch structure. The greater the number of branch chains, the higher the zero shear viscosity. On the other hand, linear chains tend to have lower zero shear viscosity. In the semi-dilute state, the presence of branches will affect zero shear viscosity if the molecular weight is considerable. This condition will depend on the type of polymer used. However, the zero shear viscosity value shows a value inversely proportional to the intrinsic viscosity value (Hwang and Kokini, 1992). This causes the lower the zero shear viscosity of the polymer, the lower the critical concentration value of the polymer (Takahashi et al., 1986). 


\section{Consistency index}

The flow consistency index value $(K)$ will be obtained based on the flow characterization by using the power law (Equation 5) or Herschel Bulkley equation (Equation 6). As shown at the inset of Figure 2d, there are at least three viscosity points at different shear rates needed in order to obtain consistency index value. The consistency index $(K)$ shows the dependence on concentration (Arora $e t$ al., 2016) and can be used to determine critical concentrations. The higher the pectin concentration, the higher the $K$ value, because the number of coils blocking the flow is getting more significant. Figure $2 \mathrm{~d}$ shows the graph model used in the prediction of critical concentration using a consistency index value. Kale et al. (2015) have demonstrated the utilization of consistency index value for measuring the same $c^{*}$ as in the general method. Morales-Contreras et al. (2020) reported the prediction of $c^{*}$ value in apple pomace pectin based on the consistency index value. Existing studies only use the consistency index parameter when the flow behavior $(n)$ of the material was Newtonian or slight shear thinning. The consistency index value represents the overall flow resistance properties at various shear rate measurements, thus the consistency index is the mean viscosity percentage (Pang et al., 2020). The unit of the consistency index value is affected by the unit of flow behavior index exponential $(n)$ from the shear rate (Equations 5 and 6), so the consistency index value method would be best used on samples that exhibit Newtonian flow or slight shear thinning behavior.

$$
\begin{aligned}
& \tau=K \gamma^{n} \\
& \tau=K \gamma^{n}+\tau_{0}
\end{aligned}
$$

\section{Specific viscosity and coil overlap parameter}

One of the frequently used methods to determine critical concentration is by plotting specific viscosity $\left(\eta_{s p}\right)$ as a function of the degree of space-occupancy dimensionless number (c $[\eta]$ ) or degree of space-occupancy (Axelos et al., 1989; Alba et al., 2015; Dimopoulou et al., 2019). Specific viscosity $\left(\eta_{s p}\right)$ is such an incremental increase of viscosity due to the presence of polymer in the solution. Normalization of specific viscosity to concentration $\left(\eta_{s p} / c\right)$ indicates the additional viscosity per unit polymer concentration. Then, the extrapolation of $\eta_{s p} / c$ to zero concentration is used to determine intrinsic viscosity $[\eta]$ (Dufresne, 2013). Intrinsic viscosity value is defined as the capability of the polymer to increase viscosity (Sayah et al., 2016). Intrinsic viscosity represents the hydrodynamic volume, thus depicting the molecular weight and hydrodynamic polymer radius (Dufresne, 2013; Yoo et al., 2006). Pectin with higher intrinsic viscosity will have a higher solution viscosity because the level of intermolecular interactions will be more significant. However, this condition is significantly influenced by the condition of the branch chain (Hwang and Kokini, 1992).

In order to determine the intrinsic viscosity, it is necessary to determine relative viscosity $\left(\eta_{\mathrm{r}}\right)$, specific viscosity $\left(\eta_{s p}\right)$, and reduction viscosity $\left(\eta_{r e d}\right)$. In general, a capillary viscometer is the most common instrument used in determining these parameters. It is a simple instrument but has good repeatability. There are several 
types of glass capillary viscometer, such as Ostwald, suspended level, and reverse flow type for an opaque solution. These three viscometers have some categorical classes with different kinematic viscosity ranges $\left(\mathrm{mm}^{2} \cdot \mathrm{s}^{-1}\right)$. Ostwald viscometer can be used for transparent pectin, with a kinematic viscosity range of $0.2-20.000$ $\mathrm{mm}^{2} \cdot \mathrm{s}^{-1}$ (Gupta, 2014). The most important thing that affects the accuracy of this method is the reading of the upper and lower meniscus. In principle, the capillary viscometer measures the time for the fluid to flow over a certain distance. Relative viscosity $\left(\eta_{\mathrm{r}}\right)$, specific viscosity $\left(\eta_{s p}\right)$, and reduction viscosity $\left(\eta_{r e d}\right)$ are calculated using Equations 7, 8, and 9, where $t$ is the time when solution drop from viscometer, $t_{0}$ is the time when solvent drop from viscometer, $\rho$ is solution density $\left(\mathrm{g} \cdot \mathrm{cm}^{-3}\right)$, and $\rho_{0}$ is solvent density $\left(\mathrm{g} \cdot \mathrm{cm}^{-3}\right)$.

$$
\begin{aligned}
& \eta_{r}=\frac{t \rho}{t_{0} \rho_{0}} \\
& \eta_{s p}=\eta_{r}-1 \\
& \eta_{\text {red }}=\frac{\eta_{s p}}{c}
\end{aligned}
$$

Intrinsic viscosity in general can be determined using a capillary viscometer. However, intrinsic viscosity can also be determined using a rheometer with modified calculation. Intrinsic viscosity can be determined by single and multiconcentrations. Wang et al. (2015) and Chen et al. (2020) have demonstrated a single concentration method to determine the intrinsic viscosity of grapefruit peel pectin and citrus pectin using the Solomon-ciuta model (Equation 10). Solomonciuta model can be used to predict intrinsic viscosity from low to high concentration. Abdel-Azim et al. (1998) reported that the Solomon-ciuta model is an accurate method as compared to other single-point models. The single concentration method is simple yet though, and it can be used in any concentration of polymer observed (Rodrigues et al., 2020).

$$
[\eta]=\frac{\sqrt{2\left[\eta_{s p}\right]-\ln \left(\eta_{r}\right)}}{c}
$$

Intrinsic viscosity determination using multi-concentration is mostly adopted in the literature and related to Huggins, Kraemer, Schulz-Blashke, and Martin's model (Equations 11-14). These models can only predict the intrinsic viscosity at low concentrations. In low concentration conditions, the coils are not overlapping. Thus, the coil capacity to increase viscosity can be well measured. Meanwhile in high concentration polymer coils are overlapping thus disturbing the measurement of pectin solution viscosity (Sayah et al., 2016). At a low concentration, the deviation can occur due to macromolecule absorption at the viscometer wall, thus decreasing polymer concentration (Abdel-Azim et al., 1998). The plotting results of each model (Equations 11-14), between $\eta_{s p} / c, \ln \eta_{r} / c$ and $\log \eta_{s p} / c$ with concentration, and between $\eta_{s p} / c$ and $\eta_{s p}$ used to be interpolated to get a linear model equation as shown inset of Figure 2e. The interpolation of these models will 
produce an intercept as an intrinsic viscosity, and the slope value from the equation of a line is a constant of the model. The model constants obtained $k_{H}, k_{K}, k_{S B}$, and $k_{M}$ are Huggins, Kraemer, Schulz-Blashke, and Martin constants. Theoretically, $k_{H}+k_{K}$ the value is equal to 0.5 and $k_{S B}$ is about 0.3-0.4 (Axelos et al., 1989; Rodrigues et al., 2020; Abdel-Azim et al., 1998; Morris et al., 1981; Zhang et al., 2016).

$$
\begin{aligned}
& \frac{\eta_{s p}}{c}=[\eta]+k_{H}[\eta]^{2} c \\
& \frac{\ln \eta_{r}}{c}=[\eta]-k_{K}[\eta]^{2} c \\
& \frac{\log \eta_{s p}}{c}=\log [\eta]+k_{M}[\eta] c \\
& \frac{\eta_{s p}}{c}=[\eta]+k_{S B}[\eta] \eta_{s p}
\end{aligned}
$$

Coil overlap parameter $(c[\eta])$ is a dimensionless number that describes a certain volume that is replaced by polymer molecules in a solution. The critical concentration can be determined by using the relationship between specific viscosity as ordinate and coil overlap parameter number $(c[\eta])$ as the basis (Figure 2e) (Kontogiorgos et al., 2012; Rao, 2007). Like other types of viscosity, the specific viscosity will change with a function of concentration. This method is the simplest and most used in various studies, especially for pectin (Sayah et al., 2016; Pancerz et al., 2020). The condition of pectin that has different flow behavior at increased concentration makes this method the best choice.

\section{Critical concentration determinations}

Based on the various methods described, two equations will be obtained from two different regimes between dilute and semi-dilute. In general, the dilute area will produce a sloping curve, thus the slope $(n)$ value will be smaller than the semidilute area (Figure 3) (Ström et al., 2014; Rayner et al., 2016). In general, the slope in the dilute regime is around $1.0\left(\mu \infty c^{\sim 1}\right)$, which can be greater or less than 1.0.

The condition in the dilute regime can be caused by a linear relationship between viscosity and concentration. Whereas in the semi-dilute regime, the resulting slope is about two to three times larger than the slope in dilute regions in general (Buathongjan et al., 2020; Methacanon et al., 2014; Lopez et al., 2015; Rayner et al., 2016; Pereira et al., 2013). This condition indicates that in a semi-dilute area, the typical increase in concentration follows the power law, where the increase is unique. One of the most critical problems after determining the appropriate method is determining the critical concentration intercept. Overall, two-line equations will be obtained from the described methods (except the dynamic viscosity pattern model), as in Equations 15 and 16. Both equations are assumed to have the same axis value ordinate $\left(y_{1}=y_{2}=y\right)$ so that they can be substituted by each other as in 
Equation 17, then it is linearized into Equation 18 to get Equation 19. Overall, from the two-line equations that have been obtained, Equation 20 can be used in all methods, while Equation 21 is used to predict the model using $\eta_{s p}$ and $c[\eta]$.

$$
\begin{aligned}
& y_{1}=a_{1} x^{n_{1}} \\
& y_{2}=a_{2} x^{n_{2}} \\
& a_{1} x^{n_{1}}=a_{2} x^{n_{2}} \\
& \ln a_{1} n_{1} \ln x=\ln a_{2} n_{2} \ln x \\
& \ln x=\ln \frac{a_{1}}{a_{2}} \frac{n_{1}}{n_{2}} \\
& c^{*}=e^{\ln \frac{a_{1}}{a_{2}} \frac{n_{I}}{n_{2}}} \\
& c^{*}=\frac{e^{\ln \frac{a_{I}}{a_{2}} n_{1}}}{[\eta]}
\end{aligned}
$$

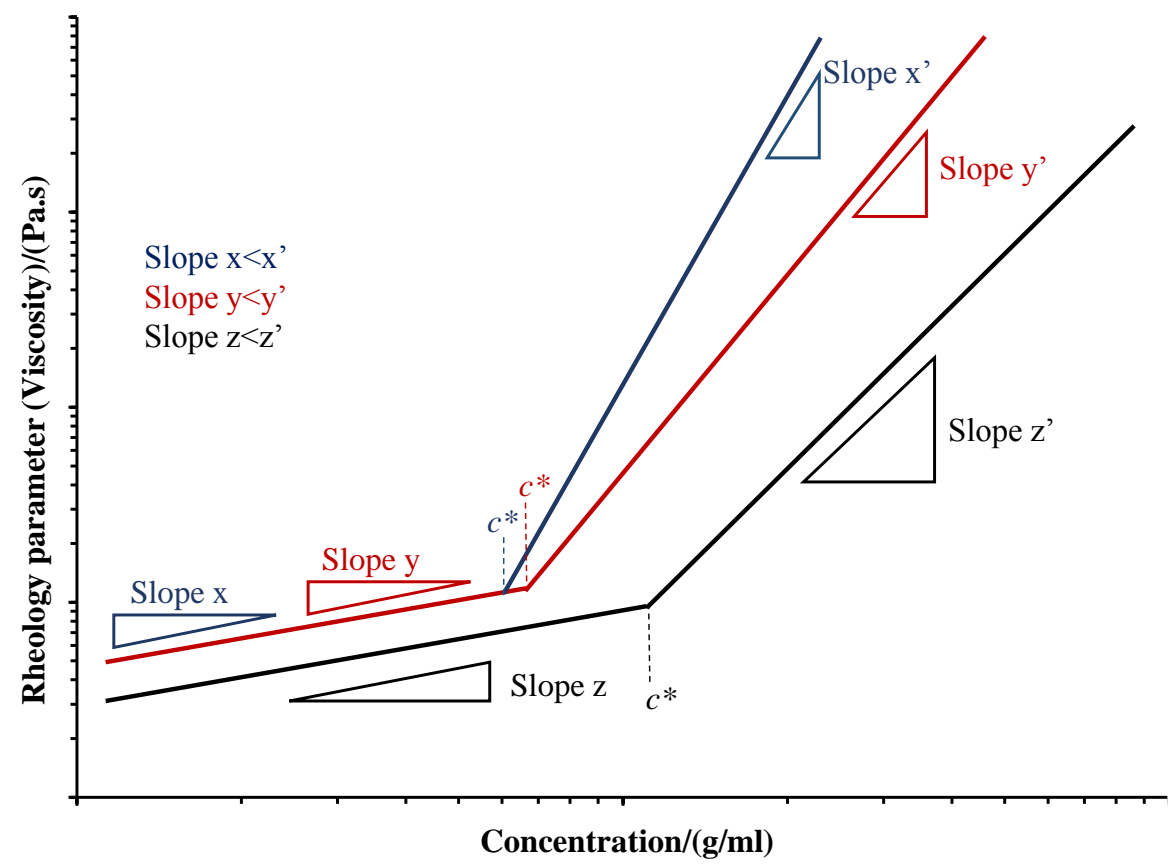

Figure 3. The illustration of the slopes to determine the critical concentration.

\section{Crucial considerations for model selection}

Based on the analysis of the existing studies, the crucial issues that need to be considered in each method were summarized in Table 2. Overall, the dynamic viscosity pattern method can be used as a preliminary method to see the presence 
of changes in viscosity increase due to changes in concentration faster. However, this method must be validated by other methods that are more suitable with the characteristics of the pectin sample. The description of the method that has been described confirms that the critical concentration can be determined using rheological parameters, such as viscosity- a parameter that follows based on the concentration function. The higher the concentration is, the higher the viscosity. But, considering the viscosity parameter alone is insufficient. The most important basic information before determining the model to be used is the flow behavior of pectin.

Table 1. Advantages and disadvantages of various model for determining critical polymer concentration.

\begin{tabular}{|c|c|c|c|c|}
\hline Methods & Advantages & Disadvantages & Instruments & References \\
\hline $\begin{array}{l}\eta_{\text {app }} v s . \\
c\end{array}$ & $\begin{array}{l}\text { - Specific shear } \\
\text { rate } \\
\text { - Suitable for } \\
\text { Newtonian or } \\
\text { slight shear } \\
\text { thinning fluid } \\
\text { - Quick } \\
\text { measurement }\end{array}$ & $\begin{array}{l}\text { - Not suitable } \\
\text { for non- } \\
\text { Newtonian } \\
\text { fluid }\end{array}$ & $\begin{array}{l}\text { - Rotary } \\
\text { viscometer } \\
\text { - Rheometer }\end{array}$ & $\begin{array}{l}\text { Liu et al. (2014); } \\
\text { Yang and Yuan } \\
(2018) \text {; Ström et al. } \\
(2014)\end{array}$ \\
\hline$\eta v s \cdot \dot{\gamma}$ & $\begin{array}{l}\text { - Provide critical } \\
\text { concentration } \\
\text { flow } \\
\text { - Direct prediction }\end{array}$ & $\begin{array}{l}\text { - Requires high } \\
\text { sensitivity } \\
\text { instrument } \\
\text { - Rough } \\
\text { prediction } \\
\text { - Need small } \\
\text { concentration } \\
\text { intervals }\end{array}$ & Rheometer & $\begin{array}{l}\text { Benchabane and } \\
\text { Bekkour (2008) }\end{array}$ \\
\hline$\eta_{0}$ vs. $c$ & $\begin{array}{ll}\text { - } & \text { Molecularly } \\
\text { representative } \\
\text { - Suitable for all } \\
\text { flow behavior }\end{array}$ & $\begin{array}{l}\text { - Requires high } \\
\text { sensitivity } \\
\text { instrument }\end{array}$ & Rheometer & $\begin{array}{l}\text { Methacanon et al. } \\
\text { (2014); Lam et al. } \\
\text { (2015); Pancerz et al. } \\
\text { (2020); Buathongjan } \\
\text { et al. (2020) }\end{array}$ \\
\hline $\begin{array}{l}\eta_{s p} \quad v s . \\
c[\eta]\end{array}$ & $\begin{array}{l}\text { - Molecularly } \\
\text { representative } \\
\text { - Does not require } \\
\text { high instrument } \\
\text { - Suitable for all } \\
\text { flow behavior }\end{array}$ & $\begin{array}{l}\text { - Depend on } \\
\text { model } \\
\text { prediction } \\
\text { type of } \\
\text { intrinsic } \\
\text { viscosity }[\eta]\end{array}$ & $\begin{array}{l}\text { Capillary } \\
\text { viscometer }\end{array}$ & $\begin{array}{l}\text { Dimopoulou et al. } \\
\text { (2019; Rodrigues et } \\
\text { al. (2020); Sayah et } \\
\text { al. (2016) }\end{array}$ \\
\hline$K$ vs. $c$ & $\begin{array}{l}\text { - Flow behavior } \\
\text { representative } \\
\text { - Suitable for } \\
\text { Newtonian and } \\
\text { slight shear } \\
\text { thinning }\end{array}$ & $\begin{array}{l}\text { - Not suitable } \\
\text { for shear } \\
\text { thinning and } \\
\text { shear } \\
\text { thickening } \\
\text { fluid }\end{array}$ & $\begin{array}{l}\text { - Rotary } \\
\text { viscometer } \\
\text { - Rheometer }\end{array}$ & $\begin{array}{l}\text { Morales-Contreras } \\
\text { et al. }(2020)\end{array}$ \\
\hline
\end{tabular}


Because of the non-Newtonian flow properties of pectin, the resulting viscosity is influenced by the shear rate used. In general, pectin has Newtonian to shearthinning flow behavior (Wang et al., 2021; Chen et al., 2020; Chen et al., 2021), so the best method to predict the critical concentration of pectin is a method that can be used for all flow behavior. The best method in general that can be used for various kinds of flow behavior and molecular representative of materials are methods that use the relationship of 1) zero shear viscosity $\left(\eta_{0}\right)$ and concentration $(c)$, and 2) specific viscosity $\left(\eta_{s p}\right)$ and a dimensionless number $(c[\eta])$. Because of the representation of the viscosity conditions without being affected by shear forces, the use of zero shear viscosity can be considered as an accurate method. Similar to a method that uses a specific viscosity $\left(\eta_{s p}\right)$ and a dimensionless number $(c[\eta])$, where the resulting viscosity value is assumed to have no additional shear forces from the outside, or it can be ignored because it does not cause significant changes. These methods can demonstrate the internal capability of the actual viscosity increase level of the material being tested and can be used as alternatives to characterize the overlapping critical concentration. All the methods described can be used to determine any fluid with shear-thinning and Newtonian flow behavior, without exception. There is also a chance that these methods can be used for other polymers by looking at the condition of the sample.

\section{Conclusions}

Critical concentration is the concentration that becomes the point of transition between two different fluid regimes, representing the interactions between the coils in solution. There are two types of critical concentrations, the critical overlap concentration $\left(c^{*}\right)$ and the critical entanglement concentration $\left(c^{* *}\right)$, but the most used is critical overlap concentration. There are five (5) methods that are commonly used to determine critical concentration based on the rheological approach. The dynamic viscosity pattern method is considered a preliminary method that needs validation by other methods. The apparent viscosity $\left(\eta_{\text {app }}\right)$ and consistency index $(K)$ method can only be used on Newtonian flow properties or less shear-thinning fluid. Specific viscosity and coil overlap parameters $\left(\eta_{s p}\right.$ and $c[\eta])$, and zero shear viscosity ( $\eta_{0}$ and concentration) methods are the most representative approaches to evaluate critical overlap concentration for pectin under various flow behaviors. The methods that use apparent viscosity parameters ( $\eta_{\text {app }}$ and concentration) and consistency index value ( $K$ and concentration) are strongly influenced by the flow behavior.

\section{Acknowledgments}

This study was funding support by the Master of Education towards Doctoral Scholarship Program for Excellence Undergraduate (PMDSU) by the Ministry of 
Research, Technology and Higher Education, Republic of Indonesia. PT. Equiva Ligand Indonesia is acknowledged for assistance to guide in studying the Anton Paar rheometer (MCR 92 and MCR 301), and Nisa Rabela for helpful discussions.

\section{References}

Abdel-Azim, A., Atta, A.M., Farahat, M.S., Boutros, W.Y. 1998. Determination of intrinsic viscosity of polymeric compounds through a single specific viscosity measurement. Polymer, 39(26), 6827-6833.

Agudelo, A., Varela, P., Sanz, T., Fiszman, S.M. 2014. Native tapioca starch as a potential thickener for fruit fillings. Evaluation of mixed models containing low-methoxyl pectin. Food Hydrocolloids, 35, 297-304.

Alba, K., Laws, A.P., Kontogiorgos, V. 2015. Isolation and characterization of acetylated LM-pectins extracted from okra pods. Food Hydrocolloids, 43, 726-735.

Arora, S.K., Patel, A.A., Kumar, N., Chauhan, O.P. 2016. Determination of relationship between sensory viscosity rating and instrumental flow behavior of soluble dietary fibers. Journal of Food Science and Technology, 53(4), 2067-2076.

Axelos, M., Thibault, J., Lefebvre, J. 1989. Structure of citrus pectins and viscometric study of their solution properties. International Journal of Biological Macromolecules, 11, 186-191.

Benchabane, A., Bekkour, K. 2008. Rheological properties of carboxymethyl cellulose (CMC) solutions. Colloid and Polymer Science, 286(10), 1173-1180.

Buathongjan, C., Israkarn, K., Sangwan, W., Outrequin, T., Gamonpilas, C., Methacanon, P. 2020. Studies on chemical composition, rheological and antioxidant properties of pectin isolated from Riang (Parkia timoriana (DC.) Merr.) pod. International Journal of Biological Macromolecules, 164, 4575-4582.

Cardoso de Castro, C.S., Santo Filho, D.M. do E., Siqueira, J.R.R., Barbosa, A.P.F., Rodrigues, C.R. da C., Cabral, M.L., da Silva, E.M., Baldner, F. de O., Gouveia, J.M.G. 2016. Evaluation of the metrological performance of two kinds of rotational viscometers by means of viscosity reference materials. Journal of Petroleum Science and Engineering, 138, 292-297.

Chan, S.Y., Choo, W.S., Young, D.J., Loh, X.J. 2017. Pectin as a rheology modifier: Origin, structure, commercial production and rheology. Carbohydrate Polymers, 161, $118-139$.

Chen, J., Cheng, H., Zhi, Z., Zhang, H., Linhardt, R.J., Zhang, F., Chen, S., Ye, X. 2021. Extraction temperature is a decisive factor for the properties of pectin. Food Hydrocolloids, 112, 106160.

Chen, J., Liu, W., Liu, C.M., Li, T., Liang, R.H., Luo, S.J. 2015. Pectin Modifications: A Review. Critical Reviews in Food Science and Nutrition, 55(12), 1684-1698.

Chen, T.T., Zhang, Z.H., Wang, Z.W., Chen, Z.L., Ma, H., Yan, J.K. 2020. Effects of ultrasound modification at different frequency modes on physicochemical, structural, functional, and biological properties of citrus pectin. Food Hydrocolloids, 106484.

Chhabra, R.P., Uhlherr, P.H.T. 1979. Estimation of zero-shear viscosity of polymer solutions from falling sphere data. Rheologica Acta, 18(5), 593-599.

Ciriminna, R., Fidalgo, A., Delisi, R., Ilharco, L.M., Pagliaro, M. 2016. Pectin production and global market. Agro FOOD Industry Hi Tech, 27(5), 17-20.

Clasen, C., Plog, J.P., Kulicke, W.-M., Owens, M., Macosko, C., Scriven, L.E., Verani, M., McKinley, G.H. 2006. How dilute are dilute solutions in extensional flows. Journal of Rheology, 50(6), 849-881. 
Codex 2018. General Standards for Food Additives, Codex Stan 192- 1995.

Colodel, C., Vriesmann, L.C., Petkowicz, C.L.D.O. 2019. Rheological characterization of a pectin extracted from ponkan (Citrus reticulata blanco $c v$. ponkan) peel. Food Hydrocolloids, 94, 326-332.

Constenla, D., Lozano, J.E. 2003. Kinetic model of pectin demethylation. Latin American Applied Research, 33, 91-96.

Cui, S.W. 2005. Food carbohydrates: Chemistry, physical properties, and applications. CRC Press, Boca Raton.

Cullen, P.J. 2012. Fluid rheology in novel thermal and non-thermal processes. In: Novel Thermal And Non-Thermal Technologies For Fluid Foods, ed. by Cullen, P.J., Tiwari B.K., Valdramidis V.P. 35-61. Academic Press, San Diego.

Dimopoulou, M., Alba, K., Kontogiorgos, V. 2019. Pectin recovery and characterization from lemon juice waste streams. Journal of The Science of Food and Agriculture, 99(14), 6191-6198.

Dufresne, A. 2013. Nanocellulose. De Gruyter, Berlin.

Einhorn-stoll, U. 2018. Pectin-water interactions in foods - From powder to gel. Food Hydrocolloids, 78, 109-119.

Einhorn-Stoll, U., Hatakeyama, H., Hatakeyama, T. 2012. Influence of pectin modification on water binding properties. Food Hydrocolloids, 27(2), 494-502.

Endress, H.U., Döschl-Volle, C., Dengler, K. 1996. Rheological methods to characterize pectins in solutions and gels. In Pectins and Pectinases, Proceedings of an International Symposium. pp. 407-423.

Erçelebi, E.A., Ibanoğlu, E. 2009. Rheological properties of whey protein isolate stabilized emulsions with pectin and guar gum. European Food Research and Technology, 229(2), 281-286.

Figueroa, L.E., Genovese, D.B. 2018. Pectin gels enriched with dietary fibre for the development of healthy confectionery jams. Food Technology and Biotechnology, 56(3), 441-453.

Fu, S., Thacker, A., Sperger, D.M., Boni, R.L., Velankar, S., Munson, E.J., Block, L.H. 2010. Rheological Evaluation of Inter-grade and Inter-batch Variability of Sodium Alginate. AAPS PharmSciTech, 11(4), 1662-1674.

Funami, T., Ishihara, S., Nakauma, M., Kohyama, K., Nishinari, K. 2012. Texture design for products using food hydrocolloids. Food Hydrocolloids, 26(2), 412-420.

Funk, J.E., Dinger, D.R. 1994. Viscosity and Rheology.

George, H.F., Qureshi, F. 2013. Newton's Law of Viscosity, Newtonian and NonNewtonian Fluids. Encyclopedia of Tribology, 2416-2420.

Gupta, S.V. 2014. Capillary viscometers. In: Viscometry for Liquids, ed. by Gupta, S.V. 45-80. Springer.

Hwang, J., Kokini, J.L. 1992. Contribution of the side branches to rheological properties of pectins. Carbohydrate Polymers, 19(1), 41-50.

Jin-hua, Z., Yu-xiong, W.U., Zhi-qiang, S. 2008. Viscous-flow properties and viscosityaverage molecular mass of orange peel pectin. Journal of Central South University, 15 520-524.

John, J., Ray, D., Aswal, V.K., Deshpande, A.P., Varughese, S. 2019. Dissipation and strain-stiffening behavior of pectin-Ca gels under LAOS. Soft Matter, 15(34), 68526866.

Kale, M.S., Yadav, M.P., Hicks, K.B., Hanah, K. 2015. Concentration and shear rate dependence of solution viscosity for arabinoxylans from different sources. Food Hydrocolloids, 47, 178-183. 
Kasapis, S., Bannikova, A. 2016. Rheology and food microstructure. In Advances in Food Rheology and Its Applications, ed. by Jasim, A., Pawel, P., Santanu, B. 7-46. Woodhead Publishing, USA.

Kontogiorgos, V., Margelou, I., Georgiadis, N., Ritzoulis, C. 2012. Rheological characterization of okra pectins. Food Hydrocolloids, 29(2), 356-362.

Kpodo, F.M., Agbenorhevi, J.K., Alba, K., Oduro, I.N., Morris, G.A., Kontogiorgos, V. 2018. Structure-function relationships in pectin emulsification. Food Biophysics, 13(1), 71-79.

Laguna, L., Manickam, I., Arancibia, C., Tárrega, A. 2020. Viscosity decay of hydrocolloids under oral conditions. Food Research International, 136, 109300.

Lam, C., Martin, P.J., Jefferis, S.A. 2015. Rheological properties of PHPA polymer support fluids. Journal of Materials in Civil Engineering, 27(11), 04015021.

Larson, R.G., Desai, P.S. 2015. Modeling the rheology of polymer melts and solutions. Annual Review Fluid Mechanics, 47(1), 47-65.

Lewicki, P.P. 2004. Water as the determinant of food engineering properties. A review. Journal of Food Engineering, 61(4), 483-495.

Li, J.M., Nie, S.P. 2016. The functional and nutritional aspects of hydrocolloids in foods. Food Hydrocolloids, 53(2016), 46-61.

Liu, J., Bi, J., McClements, D.J., Liu, X., Yi, J., Lyu, J., Zhou, M., Verkerk, R., Dekker, M., Wu, X., Liu, D. 2020. Impacts of thermal and non-thermal processing on structure and functionality of pectin in fruit- and vegetable- based products: A review. Carbohydrate Polymers, 250(2), 116890.

Liu, R., Pu, W., Jia, H., Shang, X., Pan, Y., Yan, Z. 2014. Rheological properties of hydrophobically associative copolymers prepared in a mixed micellar method based on methacryloxyethyl-dimethyl cetyl ammonium chloride as surfmer. International Journal of Polymer Science, 2014.

Lopes, L.F., Silveira, B.M.O., Moreno, R.B.Z.L. 2014. Rheological evaluation of HPAM fluids for EOR applications. International Journal of Engineering \& Technology IJETIJENS, 14(03), 36-41.

Lopez, C.G., Rogers, S.E., Colby, R.H., Graham, P., Cabral, J.T. 2015. Structure of sodium carboxymethyl cellulose aqueous solutions: A SANS and rheology study. Journal of Polymer Science, Part B: Polymer Physics. 53(7), 492-501.

Methacanon, P., Krongsin, J., Gamonpilas, C. 2014. Pomelo (Citrus maxima) pectin: Effects of extraction parameters and its properties. Food hydrocoll, 35, 383-391.

Miller-Chou, B.A., Koenig, J.L. 2003. A review of polymer dissolution. British Polymer Journal, 28(8), 1223-1270.

Monsoor, M., Kalapathy, U., Proctor, A. 2001. Improved method for determination of pectin degree of esterification by diffuse reflectance fourier transform infrared spectroscopy. Journal of Agricultural and Food Chemistry, 49(6), 2756-2760.

Morales-Contreras, B.E., Wicker, L., Rosas-Flores, W., Contreras-Esquivel, J.C., GallegosInfante, J.A., Reyes-Jaquez, D., Morales-Castro, J. 2020. Apple pomace from variety "Blanca de Asturias" as sustainable source of pectin: Composition, rheological, and thermal properties. LWT - Food Science and Technology, 117, 108641.

Morris, E.R., Cutler, A.N., Ross-Murphy, S.B., Rees, D.A., Price, J. 1981. Concentration and shear rate dependence of viscosity in random coil polysaccharide solutions. Carbohydrate Polymers, 1(1), 5-21.

Morris, G.A., Binhamad, H.A.S. 2020. Isolation and Characterisation of Pectin. In Pectin: Technological and Physiological Properties, ed. by Kontogiorgos V. Springer, Cham, pp. 61-82. 
Morris, G.A., Ralet, M.C. 2012. The effect of neutral sugar distribution on the dilute solution conformation of sugar beet pectin. Carbohydrate Polymers, 88(4), 1488-1491.

Muñoz-Almagro, N., Montilla, A., Villamiel, M. 2020. Role of pectin in the current trends towards low-glycaemic food consumption. Food Research International, 140, 109851.

Narasimman, P., Sethuraman, P. 2016. An overview on the fundamentals of pectin. International Journal of Advanced Research, 4(12), 1855-1860.

Ngouémazong, D.E., Kabuye, G., Fraeye, I., Cardinaels, R., Van Loey, A., Moldenaers, P., Hendrickx, M. 2012. Effect of debranching on the rheological properties of $\mathrm{Ca} 2+-$ pectin gels. Food Hydrocolloids, 26(1), 44-53.

Pacheco, M.T., Villamiel, M., Moreno, R., Moreno, F.J. 2019. Structural and rheological properties of pectins extracted from industrial sugar beet by-products. Molecules, 24(3), 1-17.

Pan, M.K., Zhou, F.F., Liu, Y., Wang, J.H. 2021. Na+-induced gelation of a low-methoxyl pectin extracted from Premna microphylla Turcz. Food Hydrocolloids, 110.

Pancerz, M., Kruk, J., Łukasiewicz, M., Witek, M., Kucharek, M., Jaschik, J., Ptaszek, A. 2020. Red currant pectin: The physicochemical characteristic of pectin solutions in dilute and semi dilute regimes. Food Hydrocolloids, 113, 106420.

Pang, B., Wang, S., Chen, W., Hassan, M., Lu, H. 2020. Effects of flow behavior index and consistency coefficient on hydrodynamics of power-law fluids and particles in fluidized beds. Powder Technology, 366, 249-260.

Pereira, A.S., Andrade, R.M., Soares, E.J. 2013. Drag reduction induced by flexible and rigid molecules in a turbulent flow into a rotating cylindrical double gap device: Comparison between Poly (ethylene oxide), Polyacrylamide, and Xanthan Gum. Journal of Non-Newtonian Fluid Mechanics, 202, 72-87.

Popa Nita, S., Murith, M., Chisholm, H., Engmann, J. 2013. Matching the rheological properties of videofluoroscopic contrast agents and thickened liquid prescriptions. Dysphagia, 28(2), 245-252.

Rao, M.A. 2007. Rheology of Fluid and Semisolid Foods: Principles and Applications. 2nd ed. Springer, Geneva.

Rayner, M., Östbring, K., Purhagen, J. 2016. Application of Natural Polymers in Food. In Natural Polymers, ed. by Olatunji, O. 115-161. Springer.

Rodrigues, T., Galindo-Rosales, F.J., Campo-Deaño, L. 2020. Critical overlap concentration and intrinsic viscosity data of xanthan gum aqueous solutions in dimethyl sulfoxide. Data in Brief, 33, 106431.

Rodríguez de Castro, A., Agnaou, M. 2019. Numerical investigation of the apparent viscosity dependence on darcy velocity during the flow of shear-thinning fluids in porous media. Transport in Porous Media, 129(1), 93-120.

Saha, D., Bhattacharya, S. 2010. Hydrocolloids as thickening and gelling agents in food: a critical review. Journal of Food Science and Technology, 47(6), 587-597.

Sakooei-Vayghan, R., Peighambardoust, S.H., Hesari, J., Soltanzadeh, M., Peressini, D. 2020. Properties of dried apricots pretreated by ultrasound-assisted osmotic dehydration and application of active coatings. Food Technology and Biotechnology, 58(3), 249-259.

Sayah, M.Y., Chabir, R., Benyahia, H., Kandri, Y.R., Chahdi, F.O., Touzani, H., Errachidi, F. 2016. Yield, esterification degree and molecular weight evaluation of pectins isolated from orange and grapefruit peels under different conditions. PLoS ONE, 11(9), $1-16$. 
Schmidt, U.S., Koch, L., Rentschler, C., Kurz, T., Endreß, H.U., Schuchmann, H.P. 2015. Effect of molecular weight reduction, acetylation and esterification on the emulsification properties of citrus pectin. Food Biophysics, 10(2), 217-227.

Singh, R., Heldman, D. 2009. Introduction to Food Engineering. 4th ed. Academic Press, Burlington.

Sitanggang, A.B., Wu, H.S., Wang, S.S., Lan, J.C.W. 2010. Fermentation strategies: Nutritional requirements. In Industrial fermentation: Food processes, nutrient sources and production strategies, ed. by Krause, J., Fleischer, O. 217-247. Nova Publisher, USA.

Sousa, A.G., Nielsen, H.L., Armagan, I., Larsen, J., Sørensen, S.O. 2015. The impact of rhamnogalacturonan-I side chain monosaccharides on the rheological properties of citrus pectin. Food Hydrocolloids, 47, 130-139.

Ström, A., Schuster, E., Meng, S. 2014. Rheological characterization of acid pectin samples in the absence and presence of monovalent ions. Carbohydrate Polymers, 113, 336343.

Sundar Raj, A., Rubila, S., Jayabalan, R., Ranganathan, T. 2012. A Review on pectin: Chemistry due to general properties of pectin and its pharmaceutical uses. Scientific Reports. 1(12), 10-12.

Takahashi, Y., Suzuki, F., Miyachi, M., Noda, I., Nagasawa, M. 1986. Zero-shear viscosity of branched polymer solutions. Polymer Journal, 18(1), 89-94.

Tan, H., Nie, S. 2020. Deciphering diet-gut microbiota-host interplay: Investigations of pectin. Trends in Food Science and Technology, 106, 171-181.

Vinogradov, G. V., Titkova, L. V. 1968. Critical concentrations of polymers in solutions according to measurements of the viscosity and specific surface area of aerogels resulting after sublimation of the solvent. Rheologica Acta, 7(4), 297-306.

Wang, C., Qiu, W.Y., Chen, T.T., Yan, J.K. 2021. Effects of structural and conformational characteristics of citrus pectin on its functional properties. Food Chemistry, 339, 128064.

Wang, W., Ma, X., Xu, Y., Cao, Y., Jiang, Z., Ding, T., Ye, X., Liu, D. 2015. Ultrasoundassisted heating extraction of pectin from grapefruit peel: Optimization and comparison with the conventional method. Food Chemistry, 178, 106-114.

Wolf, B.A. 2020. Shear Thinning: Determination of Zero-Shear Viscosities from Measurements in the Non-Newtonian Region. Macromolecular Chemistry and Physics, 221(14), 1-6.

Wolf, B.A. 2015. Viscosity of polymer solutions over the full range of composition: A thermodynamically inspired two-parameter approach. Industrial and Engineering Chemistry Research, 54(16), 4672-4680.

Yang, S.Y., Yuan, L.L. 2018. Advanced polyimide films. Elsevier Inc.

Yang, X., Nisar, T., Liang, D., Hou, Y., Sun, L., Guo, Y. 2018. Low methoxyl pectin gelation under alkaline conditions and its rheological properties: Using $\mathrm{NaOH}$ as a $\mathrm{pH}$ regulator. Food Hydrocolloids, 79, 560-571.

Yapo, B.M. 2011. Pectic substances: From simple pectic polysaccharides to complex pectins - A new hypothetical model. Carbohydrate Polymers, 86(2), 373-385.

Yoo, S., Fishman, M.L., Hotchkiss, A.T., Gyu, H. 2006. Viscometric behavior of highmethoxy and low-methoxy pectin solutions. Food Hydrocolloids, 20, 62-67.

Zhang, E., Dai, X., Dong, Z., Qiu, X., Ji, X. 2016. Critical concentration and scaling exponents of one soluble polyimide $\mathrm{d}$ from dilute to semidilute entangled solutions. Polymer, 84, 275-285. 
Zhang, G., Zheng, C., Huang, B., Fei, P. 2020. Preparation of acylated pectin with gallic acid through enzymatic method and their emulsifying properties, antioxidation activities and antibacterial activities. International Journal of Biological Macromolecules, 165, 198-204.

Zhong, Q., Daubert, C.R. 2013. Food Rheology. In Handbook of Farm, Dairy and Food Machinery Engineering: Second Edition, ed. by Jasim, A., Pawel, P., Santanu, B. 403426. Academic Press, Burlington. 